\title{
Hermenéutica, Metafísica, Ética* \\ La filosofía en lengua alemana durante las últimas décadas del siglo $\mathrm{XX}$
}

\author{
REINER WIEHL \\ Universidad de Heidelberg
}

\begin{abstract}
Este trabajo contiene una panorámica del pensamiento alemán posterior a la segunda guerra mundial, mostrando sucesivamente las principales corrientes y la evolución de éstas en corrientes nuevas, sea por prolongación o por contraste: el existencialismo y el marxismo de los primeros años de postguerra; la herencia fenomenológica y la crítica del cientificismo; la hermenéutica, la Escuela de Erlangen, la Escuela de Frankfurt en sus ultimas estribaciones; la vuelta del interés por la filosofía griega, particularmente por Aristóteles y la reformulación contemporánea de sus conceptos éticos; el nuevo auge de los
\end{abstract}

estudios kantianos y hegelianos; las peculiares modulaciones epistemológicas; etc.

En la segunda mitad de la exposición traza cuatro marcos temáticos particularmente significativos, dentro de cada uno de los cuales analiza las aportaciones del pensamiento alemán contemporáneo: la herencia de la filosofia trascendental como filosofía de la subjetividad; la renovación de la metafísica en una época de criticismo generalizado; la relación entre metafísica y ética; y la autocomprensión histórica de la filosofía contemporánea en el período de la modernidad y la postmodernidad.

No es sencillo perfilar una imagen global y completa de la filosofía en lengua alemana durante el último período de este siglo." A diferencia de los años que siguieron a la caída del nacionalsocialismo, esta última década se distingue por una cantidad tal de rasgos y de formas propias que parece imposible distinguir en ella nuevos contornos y líneas de desarrollo. Considerado desde la actualidad, el período inmediatamente posterior a 1945 aparece como un conjunto relativamente sencillo y bien definido. ${ }^{2}$ Con el final de la horrible y devastadora Segunda Guerra Mundial, de la que casi nadie pudo librarse, el miedo y el terror no desaparecieron por ensalmo. El sentimiento predominante era, sencillamente, el de haber sobrevivido. Eso era todo. Consiguientemente, la pregunta por el sentido de la vida se hizo más intensa. También se hizo evidente, sin embargo, que

* Traducción de Francisco Colom González. 
las ideologías y las concepciones globales del mundo eran incapaces de aportar respuestas a una cuestión semejante. Precisamente porque todavía resonaban los ecos y las imágenes de la utilización que había hecho la dictadura de esas ideologías y macrovisiones para crear y mantener el estado totalitario, no se deseaba confiar sin más en respuestas cosmovisionarias. De retorno del horror, parecía como si la búsqueda del sentido hubiera de verse siempre defraudada, como si las respuestas sólo fuesen el eco de una voz que clama desesperadamente en la oscuridad. Era la época del existencialismo filosófico, cuando sutilezas como la distinción entre sus variantes francesa y alemana poco interesaban. En el existencialismo se mostraba explícitamente lo que era un sentimiento general: que el hombre no tiene más posibilidad que el 'a pesar de' frente a un sentido fracasado de la vida y del mundo. ${ }^{3}$ También el marxismo gozó por aquellos días del más vivo interés, incluso por parte de la Iglesia, quien descubrió en el ateísmo una importante piedra de toque que permitía hacer de la fe, al ponerla en cuestión, algo más serio y veraz. ${ }^{4} \mathrm{~A}$ diferencia del existencialismo, tomado en sus rasgos típico-ideales, el marxismo no concibió al hombre en su absoluta individualidad, sino como un ser comunitario capaz de reconocer comunitariamente las condiciones de su entorno social y de mejorarlo en términos prácticos a partir de ese conocimiento. Cuando los hombres, tras unos difíciles años dedicados a la reconstrucción material, vieron que no sólo podían reparar la destrucción externa, sino terminar también con las consecuencias del miedo y la desesperanza, dirigieron entonces su mirada hacia las instancias clásicas del progreso en la modernidad: pensaron en la cultura y en la ciencia. Esta no es sólo la época en que se emprendió un vigoroso esfuerzo por superar las destructivas consecuencias de la guerra y por construir un mundo de bienestar material. También se pretendió hacer partícipes de ese bienestar y de los bienes culturales concomitantes al mayor número posible de capas sociales $\mathrm{y}$, en la medida de lo posible, a los seres humanos en general. El fundamento político-social de la democracia, que en Alemania se llevaría a cabo con mayor éxito que durante el período de la República de Weimar, exigía por igual la realización de un proyecto semejante y la asunción de las obligaciones futuras de un moderno Estado industrial. Por ello, el poderoso despeguc económico se correspondió con una tremenda expansión de las Universidades, enfrentadas por aquellos días con una misión social tan urgente que cuestionó su concepción tradicional.

La expansión universitaria de aquellos tiempos coincide también con el creciente reconocimiento encontrado por las jóvenes disciplinas universitarias que, a diferencia de las clásicas ciencias del espíritu, la filología y la historia, se consideraban a sí mismas como ciencias sociales específicamente modernas: la sociologia, la economía, la psicología y la pedagogía. Todas ellas se habían planteado como objetivo la investigación científica 
de las condiciones sociales en las que se desarrolla la existencia humana. En este ámbito general se inscribe también el gran debate filosófico de la época, que trataba nada menos que de la determinación de las posibilidades del hombre desde el punto de vista de la convivencia humana y de la sociabilidad. Pese a las discrepancias observables, los participantes en aquel debate, muy pronto fijado en diversas orientaciones escolásticas, se mantenían unidos por una doble convicción. En primer lugar, por una concepción del propio presente que difería radicalmente de la mantenida por la filosofía tras la primera guerra mundial. A diferencia de aquel entonces, no existía ahora un pesimismo cultural ni una hostilidad manifiesta contra la ciencia y la tecnología. Existía, en todo caso, una crítica del cientifismo, entendido como la pretensión de elevar la ciencia moderna a la condición de instancia absoluta de poder. En segundo lugar, las distintas escuelas filosóficas opuestas entre sí coincidían en el reconocimiento del principio dialógico, esto es, en la idea de que la inteligencia y el conocimiento humano consisten en la comprensión de los demás. En 1960 apareció publicado Verdad y método, la principal obra filosófica de HansGeorg Gadamer, sucesor de Karl Jaspers en la cátedra de Heidelberg. ${ }^{5}$ Este libro dominaría durante décadas el debate filosófico en el ámbito lingúístico alemán, antes de que su influencia se extendiera a otras partes del mundo. El autor de tan renombrado ensayo intentó conjugar en él dos tendencias contradictorias recogidas por la más reciente tradición filosófica: la ontología fundamental de Martin Heidegger en sus diversas fases de desarrollo y la fundamentación de las ciencias del espíritu llevada a cabo por Wilhelm Dilthey. De ambas prevaleció, sin duda, la última perspectiva, o al menos así se creyó entonces. Gadamer había mostrado que el hombre es un ser orientado originalmente hacia la sociabilidad y la comprensión, un ser que ha de ser entendido desde su propia historicidad. Fl hombre de la tradición cultural europea está determinado por la gran tradición filosófica que abarca desde Platón hasta Hegel, así como por los valores culturales heredados del humanismo clásico y moderno. Los esfuerzos del hombre por comprender en general, y por comprenderse a sí mismo en particular, son los que le permiten llegar a autorrealizarse, independientemente de los límites impuestos al entendimiento humano por la vinculación de todas sus experiencias a la tradición histórica. No existe ningún conocimiento histórico cerrado en sí mismo capaz de reflejar un hecho por completo. El hombre es más bien un ser histórico que choca repetidamente en su historicidad con los límites impuestos a la disponibilidad de sí mismo. Esto es algo que vale tanto para el hombre en cuanto individuo aislado como para la humanidad en su conjunto. Pero los límites impuestos a la ilustración y a la autoilustración no han de ser considerados como algo solamente negativo. Del oculto sin fondo de su ser le nace al hombre una notable capacidad configuradora con la que se enfrenta, objetivada, a tra- 
vés de sus propias obras. Frente a una ilustración reducida, los prejuicios tienen - afirmaba Gadamer - una productividad específica: la de ser susceptibles de ilustración.

Esta "legitimación" de los prejuicios presente en la obra fundamental de Gadamer provocó un debate cuyos motivos y consecuencias perduran hasta nuestros días. En el fondo se trataba nada menos que de la autocomprensión de la modernidad. No fue casual, pues, que las críticas más intensas vinieran del lado de la Escuela de Frankfurt, creada por Horkheimer y Adorno. Pero esa crítica no fue ejercida directamente por los padres fundadores de la misma, quienes en su Dialéctica de la Ilustración no se encontraban tan alejados de la primera interpretación como parecería a primera vista. ${ }^{6}$ Fue Jürgen Habermas quien se alz6 en contra del pesimismo cultural expresado por Horkheimer y Adorno en su famosa obra, así como contra la legitimación de los prejuicios realizada por Gadamer. 7 Para Habermas, el potencial ilustrador de la modernidad era bastante fuerte para asumir la contrainstancia de una sociedad crecientemente funcionalista. Se trataba de la fundamentación de una nueva praxis social capaz de y dispuesta para servirse en su provecho de la moderna ciencia positiva y de las ciencias sociales. Ideales como los de la transparencia y el diálogo libre de dominio encontraron entre la joven generación académica de aquellos años una gran aceptación. Pero la apelación al principio dialógico en el que tanto Habermas como Gadamer coincidieron recibió también apoyo por un tercer lado: la Escuela de Erlangen fundada por Paul Lorenzen. $^{8}$ El punto de partida consistía aquí en un intento de fundamentar dialógicamente la lógica, esto es, partír de un juego dialógico para llegar a un acuerdo sobre las reglas fundamentales de la comunicación. La idea de que tales reglas del entendimiento son ubicuas y que podrían aducirse para reconocer a todos los participantes en un diálogo alimentó la idea de que sería posible, en general, el aprendizaje de cualquier tipo de saber mediante la adquisición de un ortolenguaje. Así pues, lo que en aquel entonces fue sometido a debate en las tres escuelas filosóficas dominantes ha perdurado hasta nuestros días. Su centro de interés ha seguido siendo una de las cuestiones determinantes de la filosofía en lengua alemana: cómo armonizar el mundo cotidiano de la vida con el espiritu de la ciencia moderna, cómo evitar un indeseado cientifismo, esto es, la desvirtuación del mundo de la vida desde una perspectiva cientifista y tecnicista. En definitiva, cómo preservar y desarrollar frente a una actitud semejante un ethos cultural y moral fundamentado desde el mundo de la vida. La filosofía quiso contribuir a esa empresa explicando los principios y fundamentos de semejante ethos. En ese sentido fue decisiva la idea de que el mundo de la vida, el mundo de la cotidianidad, no sólo goza de autonomía frente a la ciencia, sino que posee valores y normas racionales específicas que no pueden diluirse sin más en las normas de la racionalidad científica. Si se 
desease, a modo de experimento, reducir la filosofía alemana de aquellos años a un mínimo común denominador, la fórmula sería la siguiente: la pregunta clásica por la razón humana, por las condiciones posibilitantes de un uso sensato de la razón en un mundo que parece irracional. ${ }^{9}$

Desde este punto de vista, la filosofía en lengua alemana se ha desenvuelto desde la segunda guerra mundial en un ámbito heredado de la tradición moderna y de la crítica kantiana de la razón. Los testaferros de esa herencia fueron Dilthey, con su Crítica de la razón histónica, ${ }^{10}$ y los estudios de Weber sobre la racionalidad occidental."I Pero también habría que mencionar en este contexto la gran obra tardía de Edmund Husserl, La crisis de las ciencias europeas y la fenomenología trascendental, fechada en $1937 .^{12}$ En ella, el fundador de la fenomenología asumió de nuevo el desafío planteado por su discípulo Martin Heidegger, quien en Ser y tiempo (1927) había cuestionado la racionalidad europea en general y su manifestación más característica, la metafísica, apelando precisamente a una fenomenología comprometida con la racionalidad científica. ${ }^{13}$ Heidegger había señalado ya en esa obra el radical contraste existente entre el mundo de la cotidianidad y un mundo de objetivaciones inauténticas como el de la ciencia. En las últimas dos décadas nos encontramos también con otro pensador que asumió como fundamental la herencia de Husserl: Ludwig Wittgenstein. En sus últimos escritos Wittgenstein buscó la racionalidad específica del mundo de la vida en la multiplicidad de las formas vitales, en las similitudes e interferencias entre sus formas. Si la imagen de la filosofía alemana durante aquellas primeras décadas parece más unitaria y coherente que la de estos últimos años, ello se debe ante todo a una ley de perspectivas histónicas: bajo condiciones similares de complejidad, la perspectiva más temprana y distante parece más sencilla que la más reciente y próxima a nosotros. Pero esta ley de perspectivas históricas no excluye auténticos cambios de contenido. De hecho, no es posible obviar un profundo cambio de estilo, una transformación de las actitudes mentales en la filosofía escrita en alemán durante los últimos años. El núcleo de interés se ha desplazado de la macrología a la micrología, tanto en el seno de las investigaciones filosóficas sistemáticas como en el de las históricas. Incluso alli donde la investigación filosófica vincula conscientemente la perspectiva sistemática a la histórica, donde lo pasado se funde con lo presente en un horizonte unitario y donde se buscan nuevas preguntas y respuestas a partir de los planteamientos clásicos, predomina ahora el interés por los detalles exactos y por formas micrologicas de representacion. Edmund Husserl fue el último en pretender seriamente fundamentar la filosofía como una ciencia estricta y diferenciarla, a su vez, de la exactitud de las ciencias positivas individuales. Desde que Heidegger renunciara en Ser y tiempo al ideal de la fenomenología como una ciencia estricta, una cuestión se mantiene abierta en la filosofía alemana: qué puede ser la filosofía 
si no es una ciencia, una concepción del mundo ni una ideología. La ubicua tendencia hacia la exactitud micrológica aparece desde este punto de vista como una especie de compensación por las carencias del conocimiento filosófico.

En lo que se refiere a la citada ley de la perspectiva histórica, siempre resulta difícil, cuando no imposible, señalar en el presente dónde terminan las viejas corrientes filosóficas y dónde comienzan los nuevos desarrollos. De hecho, en la filosofía alemana de los últimos años pueden observarse los rasgos constitutivos de un proceso muy particular: en primer lugar, la pervivencia de una tradición clásica que es reconocida como tal; en segundo lugar, una conciencia de lo olvidado unida a la anámnesis de lo que fue violentamente reprimido en su día; por último, aunque no menos importante, el surgimiento de líneas nuevas de investigación. Este juego entre lo antiguo y lo nuevo tiene, como todo en filosofía, su componente histórico y su componente sistemático. Hoy, al igual que siempre, əl interés por la filosofía griega sigue jugando un papel importante, en parte todavía por la influencia del pensamiento de Gadamer y de Heidegger. En cuanto al estudio de la filosofía platónica, no se puede menos que mencionar la recuperación que llevaron a cabo Gaiser y Krämer, los filólogos clásicos de Tubinga, de la vieja tesis sobre la "doctrina no escrita" de Platón, cuya formulación provocó las críticas de los seguidores del Platón dialógico de Schleiermacher. ${ }^{14}$ Pero, por encima de todo, ha sido Aristóteles quien ha destacado como un clásico contemporáneo. Si bien en Ser y tiempo se adivinaban ya claramente las huellas aristotélicas de Heidegger, la publicación, actualmente en curso, de su obra completa ha proporcionado una abrumadora confirmación de la renovada actualidad de Aristóteles. ${ }^{15}$ Esa actualidad no se limita en absoluto al corpus de sus textos metafísicos. Gadamer y algunos de sus discípulos han redescubierto la utilidad del principio aristotélico de la prudencia para enfrentarse al rigorismo de la doctrina moral kantiana. ${ }^{16}$ Robert Spaemann ha aportado convincentes argumentos para una relectura de la eudemonía y del significado de la doctrina aristotélica de los principios a la luz de una filosofía biológica. ${ }^{17} \mathrm{Si}$ se habla de la pervivencia de tradiciones clásicas en la filosofía escrita en alemán, hay que mencionar entonces la tradición filosófica que es portadora del calificativo 'alemán' por antonomasia y que abarca toda una época del pensamiento desde Kant hasta Hegel: me refiero al «idealismo alemán». Sobre esta época y sobre sus principales autores disponemos de excelentes estudios individuales, de destacados trabajos de investigación, como los del Hegel-Archiv en Bochum, dirigidos por Otto Pöggeler, y de estimulantes congresos de nivel mundial organizados por la Asociación Internacional para el Estudio de la Filosofía de Hegel, presidida por Dieter Henrich. ${ }^{18}$ Del estudio del idealismo especulativo han surgido continuamente nuevos debates filosóficos. Así, por ejemplo, sobre la 
postura política de Hegel en su filosofía del derecho, una discusión motivada por el hallazgo de diversas notas lectivas desconocidas hasta el momento. ${ }^{19}$ Lo mismo se puede decir del continuo esfuerzo por utilizar la tcoría de la autoconsciencia de Kant y de Fichte como base para el desarrollo de nuevos marcos filosóficos..$^{20}$ El Yo humano, en su forma de autoconsciencia, aparece en esa tradición actualizada como el lugar más señalado para la comprensión de la humanidad en sus dimensiones individual y colectiva.

La lista de los temas filosóficos olvidados o reprimidos y rescatados durante las últimas décadas del olvido y del exilio es tan larga, en principio, como la de todos aquellos temas que cayeron víctimas de las proscripciones de la dictadura nacionalsocialista. La gran tradición neokantiana, dominante en el pensamiento filosofico durante la segunda mitad del pasado siglo y comienzos del presente, ha de ser reconsiderada a partir de la influencia ejercida por la obra de Martin Heidegger. Heidegger opuso al criticismo de la filosofía trascendental kantiana, al que se mantenían apegadas las distintas escuelas del neokantismo, la renovación misma del enfoque metafísico. Para semejante empresa de renovación tomó nada menos que a Kant como testigo principal. Es difícil imaginarse la suerte que habría corrido la obra Filosofía de las formas simbólicas de Ernst Cassirer, último miembro del neokantismo, de no haber tenido que emigrar éste desde Alemania. Igual de difícil resulta apreciar el interés que se observa en Alemania por una tradición filosófica que arranca de los fundamentos del idealismo kantiano y de la filosofía lingüística de Humboldt para llegar hasta la semiótica, las formas míticas y la fundamentación de una antropología cultural. ${ }^{21}$ También la obra de Sigmund Freud se encuentra entre los redescubrimientos posteriores a la Segunda Guerra Mundial. Su reapropiación en el ámbito lingǘstico alemán ha sido tan intensa y amplia que su obra se ha convertido en materia de formación general para las disciplinas filosóficas y psiquiátricas. De todas formas, la literatura filosófica en alemán sobre Freud no puede compararse con la francesa en lo que se refiere a riqueza y profundidad de la discusión. ${ }^{22}$ Otra de las recuperaciones más importantes que habría que señalar en el ámbito alemán es la de Franz Rosenzweig. ${ }^{23}$ El nombre de Rosenzweig no sólo representa el último gran intento por crear una simbiosis cultural entre el judaísmo y el germanismo. Constituye quizá también el último gran esbozo filosófico de una religiosidad judía y cristiana unitaria en el contexto de la tradición filos6fica europea, una tradición que obedece a un doble origen religioso y que remite la filosofía griega a un ámbito preterrenal cuya influencia todavía perdura y perdurará. El gran proyecto de Rosenzweig se nutría de dos fuentes filosóficas. Por una parte, de la filosofía tardía de Schelling, en particular de su distinción entre una filosofía negativa y una filosofía positiva, esto es, una filosofía de la mitología y una filosofía de la revelación. 
La otra fuente es el pensamiento filosófico de Hermann Cohen, quien en su gran obra póstuma sobre las fuentes judaicas de la religión racionalista realizó una profunda revisión del kantismo en lo referente a las relaciones entre ética y religión.

Un ámbito muy distinto es el constituido por la tradición científica del neopositivismo, y en particular por la del Círculo de Viena, cuya resonancia cn los Estados Unidos llegó a ser notoria. En las reflexiones filosóficocientíficas habría que distinguir especialmente aquellas que han marcado de forma decisiva las pautas posteriores del desarrollo de la filosofía en lengua alemana. En primer lugar destaca la citada perspectiva neopositivista, cuyo foco de atención gira en torno a la formulación de los conceptos y las teorías científicas, a la influencia de las propias teorías en la interpretación de los datos y a los problemas metodológicos y de evaluación de las mediciones. Una línea filosófica distinta es la que partió de estas consideraciones para adentrarse paulatinamente en una filosofía de la naturaleza y en una metafísica cosmológica. Los padres de la primera perspectiva fueron Carnap, Reichenbach, Schlick, etc. Los de la segunda, fundamentalmente Alexander y A.N. Whitehead. En ambos campos, la filosofía germanoparlante ha realizado importantes avances. ${ }^{24}$ Particular mérito ha de reconocérsele en este contexto a $\mathrm{W}$. Stegmüller, quien ha recogido en un trabajo de carácter auténticamente enciclopédico el conjunto de las reflexiones teórico-científicas hasta la fecha. ${ }^{25}$ Este autor ha sido el primero en llamar la atención sobre la importancia de la metafísica cosmológica de Whitehead para la filosofía contemporánea. ${ }^{26}$ Pero si dirigimos nuestra atención hacia los trabajos auténticamente novedosos en el ámbito lingüístico alemán hemos de referimos entonces a la influencia ejercida por la denominada "filosofía analítica", que desde Inglaterra alcanzó a todo el mundo angloparlante.

No obstante, la gran figura integradora de las distintas corrientes de filosofía analítica fue la del austriaco Ludwig Wittgenstein, cuya influencia sobre la filosofía alemana es inimaginable y sólo puede compararse a la de Martin Heidegger. No es casual, pues, que las nuevas generaciones filosóficas hayan querido reconocerse en el ámbito inaugurado por la filosofía analítica, un ámbito que se remonta, por lo demás, a los comienzos de este siglo. Para esta generación, el espíritu de la filosofía analítica consistía precisamente en una perspectiva micrológica que venía a sustituir a la filosofía de grandes ambiciones. Se trataba de una nueva filosofía de pasos cortos que parecía hacer las ideas más abarcables, más controlables en términos lógicos e incluso les concedía un estatus cuasi-científico. No obstante, los efectos corruptores de la filosofía analítica se hicieron evidentes tan pronto como mostró su reactividad a las consideraciones históricas. Las generaciones más jóvenes prescindieron así de todo saber de tipo formativo y recelaron incluso de la formulación de concepciones globales. En 
este sentido fue Emst Tugendhat quien, con sus lecciones de Heidelberg, más contribuyó al reconocimiento filosófico de la tradición analítica anglosajona. ${ }^{27}$

Pero la filosofía alemana más reciente no sólo ha influido en el panorama filosófico contemporáneo a través de investigaciones aisladas. ${ }^{28}$ Un análisis más detallado permite distinguir una serie de cuestiones y problemas centrales que han servido como eje de vertebración. Por encima de todo destaca el ya citado "principio dialógico", cuya relevancia no sólo se ha puesto de manifiesto en los desarrollos fenomenológicos. Este principio ha servido asimismo de fundamento para planteamientos tan diversos como la perspectiva hermenéutica de Gadamer, la teoría comunicativa de Jürgen Habermas y la pragmática trascendental de Karl Otto Apel. ${ }^{29}$ Un segundo principio relevante es el del «lenguaje», que en la filosofía alemana ha confluido con el "giro lingüístico» del pensamiento anglosajón. El lenguaje como principio ha encontrado múltiples usos. Por una parte, ha actuado como contraprincipio frente a los fundamentos de la filosofía clásica, que creyó poder fundar el conocimiento sobre la instancia del pensamiento puro. Por otra parte, no son necesarios grandes esfuerzos para considerar el lenguaje científico como un lenguaje más y comprometer a la filosofía en la crítica lingüística, desvinculándola así de su función clásica como crítica de la razón. El tercer principio fundamental es el de la racionalidad. En este sentido, el desafío a la racionalidad científica no viene dado sólo por la diversificación de la ciencia, por la inconmensurabilidad de sus contomos, sino por la infinita posibilidad de sus aplicaciones tecnológicas y por los numerosos interrogantes que plantea la inteligencia artificial..$^{30}$ Pese a ello, son cuestiones como el sentido de la vida cotidiana, la posición del hombre en el mundo y su conducta frente a los demás las que exigen un replanteamiento del problema de la racionalidad, de sus límites y posibilidades. La toma en consideración de estos principios nos conduce necesariamente a otros problemas entre los que destacan, por su significación filosófica, los siguientes: 1) la herencia de la filosofía trascendental como filosofía de la subjetividad; 2) la renovación de la metafísica en una época de criticismo generalizado; 3) la relación entre metafísica y ética; 4) la autocomprensión histórica de la filosofía contemporánea en el período de la modernidad y la postmodernidad. Estos problemas se encuentran, evidentemente, entrelazados entre sí. Así, por ejemplo, la filosofía de la subjetividad remite al problema fundamental de la metafísica, de igual manera que la ética debe plantearse si es posible su fundamentación prescindiendo de toda metafísica o tiene, por el contrario, que descansar necesariamente sobre supuestos metafísicos. Entre todas estas cuestiones no es posible 
obviar una última: dónde nos encontramos los hombres del siglo $\mathrm{xx}$ y qué lugar desea asignarnos y asignarse a sí mismo el pensamiento filosófico.

\section{La filosofía trascendental de la subjetividad}

Bajo este título pueden subsumirse todos los esfuerzos vinculados a la tradición clásica del pensamiento filosófico que intentaron determinar el ser del hombre partiendo de los conceptos del Yo y de la autoconciencia. El Yo humano en su conciencia y en su autoconciencia funcionó tradicionalmente, y sigue funcionando, como fuente de la racionalidad y como fundamento de la especial apertura humana hacia el mundo. Esa apertura le permite al ser humano trascender los límites fijados por su entorno y remitirse en su totalidad al ámbito de lo trascendente. El problema de la filosofía clásica comienza por la mera determinación conceptual de ese Yo, el cual debe constituir el lugar y el fundamento de la verdad teórica y práctica de la razón. Desde que Fichte intentara esa determinación conceptual, sus aporías y antinomias no han dejado de repetirse. Si se intenta concebir el Yo humano como aquello que es a través de la capacidad para reflexionar sobre sí mismo y que sólo existe en la reflexión realizada, se plantea entonces la cuestión de cómo puede existir en absoluto un Yo semejante si, por una parte, éste sólo es lo que es mediante la reflexión y, por otra, la reflexión no es nada si no es reflexión del Yo. También aquí parece inevitable considerar la cuestión planteada por Hegel: la de si con el concepto de reflexión y con los demás conceptos que aluden a una relación consigo mismo se afecta realmente a la esencia del Yo humano en sus características fundamentales. Con otras palabras, si la noción de un ser vital no exige de antemano la capacidad de reflexionar sobre sí mismo, de establecer una autodistinción frente a los demás, remitiendo con ello el Yo humano a un universo conceptual distinto. El planteamiento del Schelling maduro fue el último en intervenir en el debate filosófico sobre la subjetividad humana. Con él se planteó el problema de si por detrás de toda reflexividad, de todos los esfuerzos por sondear el misterio del propio ser a través de la relación consigo mismo, no se renueva siempre el irresoluble misterio de la existencia, cuya respuesta nunca nos la proporcionará el pensamiento conceptual. ${ }^{31} \mathrm{El}$ problema filosófico del Yo se hizo más agudo en este siglo con la crítica radical a que sometió Nietzsche el concepto tradicional de verdad. Max Scheler y Martin Heidegger cuestionaron bajo su influencia el carácter supuestamente primigenio del Yo afirmado como condición y conciencia de sí mismo, minando con ello la fundamentación cartesiana de la filosofía moderna. Para Scheler, la autoconciencia humana críticamente fundamentada era insuficiente como fuente relevante de la verdad y del auténtico conocimiento de sí misma. Esa autoconciencia era tambiến para él origen de autoengaños y de falsos ídolos del 
conocimiento. Pero Heidegger fue más allá en sus consideraciones. Él no pretendía concebir la existencia humana partiendo del autoconocimiento, sino orientar esa idea en un sentido eminentemente teórico o práctico. Por eso no habló ya de autorreflexión al aludir al Dasein humano: determinó ese Dasein como un Seiendes cuyo Sein consiste precisamente en ser. El ser del Dasein aparece fijado terminológicamente en su obra como Existenz, y toda forma posible de existir como "inquietud" (Sorge). La inquietud del Dasein humano se enfrenta con un número inconmensurable de posibilidades: posibilidades abiertas y ocultas, frustradas e insatisfechas, pero también posibilidades auténticas. La conciencia y la autoconciencia como formas para la comprensión teórica y práctica del conocimiento objetivo ya sólo gozaban ahí, en cuanto conceptos derivados, de una limitada validez filosófica. Pero, más allá de estos inconvenientes, la filosofía contemporánea de la subjetividad en lengua alemana ha tenido que enfrentarse con un nuevo obstáculo cuyo origen se encuentra también en un clásico germánico de nuestro siglo: Ludwig Wittgenstein. La obra de Wittgenstein ha visto reforzada su influencia precisamente a través de la filosofía analítica anglosajona. Para este autor resultaba sumamente cuestionable la idea de una esfera humana especial que goza de un acceso privilegiado a su mundo interior, independientemente de que ese acceso desemboque en error o en certeza. En la medida en que partió del lenguaje hablado y concibió los significados lingüísticos como una consecuencia del cumplimiento de las reglas de lo hablado, Wittgenstein dudaba que la esfera de la interioridad fuese algo más que una extrapolación paco fiable de lo hablado. Ciertamente tenía y tiene sentido que alguien hable de sus intenciones o planes y se refiera a ellos en general como 'míos' o 'o mío', pero de ahí no se desprende que tenga un acceso privilegiado a lo suyo, sino más bien un conocimiento especial de ello. Yo hablo de mis dolencias como hablo también de esta o de aquella persona. Esta forma de hablar se corresponde con las diferencias de significado entre lo mío y lo suyo, pero son diferencias pertenecientes a un lenguaje que une entre sí a un gran número de personas en un mundo de vida común. En este contexto, también el concepto básico de la filosofía trascendental, el de la autoconciencia, carece para Wittgenstein de toda virtualidad fundamentadora. Sin embargo, pese a las objeciones mencionadas, la filosofía trascendental se ha conservado en la filosofía alemana contemporánea de forma diversa. Por un lado, Dieter Henrich ha defendido decididamente la autoconciencia como principio fundamental de la modernidad frente a las críticas de Ernst Tugendhat, apoyadas en los argumentos de Heidegger y Wittgenstein. ${ }^{32}$ Mientras que Henrich pretendía reconstruir el citado principio y los problemas que le son inherentes, como por ejemplo el de la identidad y el de la autorreflexión, Tugendhat buscaba más bien una reforma del mismo que incorporase las objeciones aludidas. Otro ejemplo de la herencia de la filosofía tras- 
cendental lo constituye el proyecto, continuamente renovado, de Karl Otto Apel sobre una pragmática trascendental. Frente a la figura de Wittgenstein, aquí es Ch.S. Peirce el padrino intelectual, cuya obra ha hecho Apel accesible al gran público alemán mediante la publicación de una serie de textos seleccionados. ${ }^{33}$ La pragmática trascendental prescinde intencionadamente de la recepción que tuvo Kant en el ámbito de la hermenéutica. Esta pretendía darse por satisfecha con una reflexión crítica sobre el mundo de la vida y su ethos correspondiente. La pragmática trascendental, por el contrario, pretende más bien constituirse en el fundamento filosófico de ese ethos con la ayuda de un instrumental distinto al de la deducción trascendental idealista. Los sujetos trascendentales deben construir en este caso una comunidad de entendimiento, pero no aportando cada uno de ellos unos determinados trascendentales con el fin de lograr la reflexión, sino poniéndose de acuerdo sobre los trascendentales aceptables por todos a través de un discurso pragmático y a la vez fundamentador.

\section{La renovación de la metafísica}

La tesis del final de la metafísica procede de la filosofía alemana del siglo

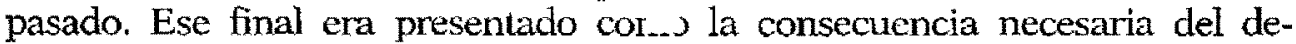
rrumbe de los grandes sistemas especulativos del idealismo. El hegelianismo de izquierdas y el neokantismo contribuyeron por igual, pese a sus diferencias internas, a propagar esta tesis a lo largo del siglo Xrx. Ambos deseaban ver en el criticismo la forma filosófica que sustituyese a la metafísica. Con el cambio de siglo, y particularmente a partir de la primera guerra mundial, la citada noción cobró un impulso cada vez mayor. A ello contribuyó la idea de que la metafísica y la tradición cultural europea se encontraban en una relación más íntima de lo que hasta entonces había reconocido la teoría filosófica. En favor de este punto de vista jugó una baza importante el pensamiento de Nietzsche, bajo cuyo influjo expuso Oswald Spengler su tesis sobre la «decadencia de Occidente». Pero ya con anterioridad Dilthey había dedicado buena parte de su obra científica a la explicación histórica del significado cultural de la metafisica en la modernidad europea. A esta misma tradición pertenece, como heredera del hegelianismo de izquierdas, la idea de Horkheimer sobre una «teoría crítica» que renuncia para su fundamentación a la ontología y a la metafísica. En cualquier caso, tras la Gran Guerra existían tantas corrientes filosóficas opuestas que parecía justificado hablar de una renovación de la metafísica. En ese contexto se inscribe la obra de Max Scheler, uno de los primeros en enfrentarse con el pragmatismo de la filosofía americana de aquellos años. Igualmente hay que mencionar aquí la extensa obra de Nikolai Hartmann, con la que se llevó a cabo de forma expresa el tránsito desde la gnoseología crítica a la ontologia y la metafísica. Hartmann se esforzó asimismo por destacar la figura de Aristóteles frente al 
neokantismo y su pretensión de hacer valer a Platón como único antecesor legítimo del criticismo contemporáneo. Sin embargo, hay que recordar que la renovación del pensamiento metafísico en el ámbito linguístico alemán no se debe a Scheler, a Hartmann o a algún otro nuevo metafísico. Se debe precisamente a quien se opuso a esa nueva forma de pensamiento metafísi$\mathrm{co}$, que para él no era sino una repetición de la vieja y ya superada metafísica: Martin Heidegger. ${ }^{34}$ Fue Heidegger quien acuñó el término de "destrucción de la metafísica", convertido casi en una expresión de moda en la filosofía francesa contemporánea. Pero para Heidegger, la destrucción de la metafísica no equivalía a una destrucción desde la raíz: se trataba tan sólo de una parte, de un momento en la reconsideración de la metafísica tradicional. Según su interpretación, la metafísica europea - ese núcleo de la cultura occidental-_ no había llegado nunca a comprender su verdadero ser. Para tal comprensión hubiera sido necesario retroceder en la determinación de los orígenes de su ser. La destrucción de la metafísica pretendía ser algo más que una mera radicalización del criticismo, tal y como proponía la filosofía neokantiana. Debía más bien posibilitar ese paso atrás que hiciera visible algo del oculto ser de la metafísica y, con ello, algo del ser de la historia europea.

Con una obstinación sin par Heidegger planteó repetidamente la misma pregunta: la pregunta por el Sein del Seiendes, esto es, por el sentido del ser. Heidegger sabía perfectamente que esa había sido la pregunta de la metafísica tradicional, aunque afirmase que era una pregunta nunca planteada hasta entonces. Al reformular una cuestión ya planteada por Platón y Aristóteles, Heidegger deseaba cvitar perderse en la historia de las respuestas aportadas. De ahí su no menos obstinado énfasis en la pregunta que debía preceder a cualquier metodología en la respuesta. Con ello concedió al pensamiento sobre el ser una innovadora forma metodológica, una metodología consistente en buscar y en descubrir sirviéndose para ello, de forma un tanto desconcertante, del método fenomenológico de Husserl. La influencia directa e indirecta de Ser y tiempo, la principal obra de Heidegger, sobre la filosofía en lengua alemana no puede ser suficientemente valorada. Superó sobradamente el influjo ejercido por el pensamiento de Jaspers, independientemente de la proximidad y del parentesco que existe entre ambas obras. Un éxito semejante sólo se explica, al menos en parte, por la extraordinaria expresividad de su forma de representación y por unos teoremas filosóficos que arrojaron luz sobre ciertas cuestiones dando, por consiguiente, "mucho que pensar». Entre esos descubrimientos filosóficos se cuentan, entre otros, los siguientes: la representación de las verdades que se muestran en el trato cotidiano con las "cosas accesibles"; el esfuerzo por trascender la distinción kantiana entre el conocimiento teórico y el conocimiento práctico de la verdad, esto es, la tesis de que el entendimiento y la existencia humana mantienen una originalidad equiva- 
lente; la idea de que la diferencia ontológica fundamental entre Sein y Seiendes atraviesa el ser de todo comportamiento humano, particularmente y de forma ejemplar su determinación por el miedo y el temor. También fue nuevo e inusual el análisis existencial heideggeriano de la temporalidad. El tiempo ya no era entendido primordialmente como una forma de la preteridad de las cosas. Tampoco como el tiempo medido de los acontecimientos en el mundo ni como un dato psíquico proporcionado por la memoria, la representación y la anticipación. Heidegger pretendía más bien concebir el tiempo como lo existencial en la existencia histórica del hombre, como éxtasis e irrupción de la interioridad en el tenso ámbito de la existencia auténtica e inauténtica. Particularmente importante para este pensamiento metafísico renovado fue el redescubrimiento del concepto ontológico del mundo. Con ello Heidegger pretendía diluir ese concepto en un mero principio regulativo de experiencias objetivadas, tal y como había propagado el neokantismo. En la medida en que concebía el Dasein humano como algo arrojado a y existente en el mundo, la propia representación del mundo sólo podía tener validez para Heidegger como algo derivado. Así se mostraba que el Dasein humano se encuentra siempre en un entorno en el que puede volver a perderse y en el que se enfrenta con entramados de significado que abren su capacidad para trascender el mundo. La influencia de Heidegger no se debió sólo a este inusual y excitante teorema extraído de Ser y tiempo, sino a su vigorosa y provocadora interpretación de la tradición metafísica. Clásicos como Platón y Aristótcles, Descartes y Kant, pero también contemporáneos suyos como Husserl y Scheler, se convirtieron para él en representantes de un problema sobre el que proyectó su propio planteamiento. En la filosofía de todos estos autores reencontró un pensamiento ontológico que había perdido su sentido original al quedar liado en la red de conceptos de la metafísica tradicional.

El pensamiento ontológico de Heidegger supone una violenta ruptura con la filosofía del idealismo alemán, no sólo con la tradición de la filosofía trascendental kantiana, sino incluso con la filosofía especulativa de la historia de Hegel. Frente a la idea de una historia que progresa en la conciencia de la libertad, Heidegger opuso conscientemente una historia del ser como juego con el destino del hombre entre lo oculto y lo manifiesto. Pero Heidegger fue más allá en sus esfuerzos por romper con la tradición filosófica. Siguiendo los pasos de Nietzsche, concibió la metafísica en su totalidad como una forma de platonismo, como la diferencia entre un mundo presente y un mundo trascendente, una diferencia de la que nacen por igual la teología, el moralismo y el nihilismo. Bajo la influencia de Nietzsche, vio en la metafísica un callejón sin salida para el pensamiento, no ya un "paseo por el bosque», como denominaba a la ruta de su teorización sobre lo desconocido. Heidegger desconocía las alternativas metafísicas de su época frente a la tradición, pero tampoco deseaba conocerlas, 
puesto que lo que pretendía, en definitiva, era una «inversión», una alternativa teórica al pensamiento metafísico tradicional. Pero fue su propio pensamiento el que se manifestó finalmente como un callejón sin salida. Esto es algo que el propio Heidegger reconoció antes y de forma más clara que muchos otros. Ante esta conclusión reaccionó con lo que él mismo denominó una «inversión» en su forma de pensar: a través de su intencionado esoterismo pretendió arrancar definitivamente a ésta del poder de la tradición europea. ${ }^{35}$ Su pensamiento se negaba conscientemente a toda posible mediación e imposibilitaba ser continuado. La hermenéutica filosófica de H.G. Gadamer constituye en realidad un paso en el sentido de esa inversión, ya que con ella dio un giro ontológico al pensamiento lingüístico. De acuerdo con ese giro, la creación de significado por la subjetividad humana sólo puede ser entendida desde los datos lingüísticos. Pero Gadamer se vio obligado a abandonar el camino filosófico abierto por Heidegger en su pretendido seguimiento de Nietzsche. Consiguientemente, asumió de Heidegger la idea de que el comportamiento humano se muestra ante todo en el lenguaje, en el entendimiento y en la interpretación, pero vinculó esas formas de conducta a los valores y normas fundamentales de la filosofía clásica. Las vinculó, en definitiva, a los mismos valores fundamentales del humanismo europeo que Heidegger creyó necesario abandonar en favor de una originalidad supuestamente más profunda. La denominada hermenéutica filosófica proveyó por consiguiente a la ontología de una buena dosis de pragmatismo y renovó el debate abierto por el neokantismo y por Dilthey en torno a los principios fundamentadores de las ciencias del espíritu. Con ello se replanteó cn cl ámbito lingúístico alemán la discusión clásica sobre la comprensión y la explicación como formas de conocimiento. En su primera versión, Max Weber y Karl Jaspers ya indicaron que consideraban la determinación de las relaciones entre ambos enfoques como la función más importante del conocimiento. ${ }^{36}$

\section{De la metafísica a la ética filosófica}

La metafísica en el mundo germánico no siguió el camino trazado primeramente por Heidegger, algo difícil por las razones ya aducidas. Así, por ejemplo, Wolfgang Cramer, enconado oponente de la Teoría Crítica y de Heidegger por igual, buscó desde el neokantismo de Breslau un nuevo camino entre la teoría idealista de la subjetividad y la ontología fundamental. ${ }^{37}$ Su Fundamentación de una teoría del Espíritu partía del concepto neokantiano de creación, si bien le concedió a este término un nuevo giro ontológico. Con él pretendía construir una metafísica de la subjetividad sobre los conceptos de la vivencia y de la autocreación, pero sustrayendo las condiciones posibilitantes de las mismas a la experiencia. Más importante para la renovación del pensamiento metafísico en el ámbito germáni- 
co fue el redescubrimiento de la obra tardía de A.N. Whitehead. La filosofía en alemán ha seguido con esa orientación hacia Whitehead un camino distinto al de la teología procesual americana. La significación del pensamiento cosmo-psicológico del Whitehead maduro para la tradición filosófica alemana se ha hecho notar en una serie de temas. En primer lugar, la filosofía trascendental no tuvo que presentarse ya en ese contexto como el umbral de una época. Ello permitió el reconocimiento abierto de la metafísica racional, tan criticada anteriormente, y de sus vínculos tradicionales con la antigua filosofía platónica y aristotélica del logos. Un análisis más detallado muestra, no obstante, que la crítica ilustrada de la razón, en no menor grado que la crítica kantiana y el criticismo en general, permanecieron presos de la tradición metafísica que debían precisamente superar. Lo mismo ocurrió con la filosofía de la subjetividad, sustituta de la vieja ontología de la sustancia. La historia de la filosofía no se presenta en absoluto, pues, como un progreso lineal, ya sea en el ámbito de la metafísica o en el de otro pensamiento no metafísico, por ejemplo el meta-metafísico. Precisamente porque la historia de la metafísica europea se encuentra indisolublemente unida a la historia de su cultura, carece de sentido pretender anular aquélla de un solo trazo. Precisamente porque su historia es la historia de una combinación de verdades y errores, resulta más imperioso que nunca el bosquejo de una alternativa metafísica. El error básico de la metafísica tradicional no consiste tanto en haberse equivocado sobre la diferencia ontológica entre el Sein y el Seiendes, algo inevitable e inherente al ser de la metafísica, sino en haber confundido lo abstracto con lo concreto. Atendiendo a la actitud frente a ese error puede hablarse de un nuevo ethos del pensamiento metafísico. De acuerdo con él, el pensamiento renuncia conscientemente a todo intento de derivar y explicar lo concreto a partir de lo abstracto. A su base se encuentra la idea de una filosofía de lo concreto consciente de que, al final, una derivación y una explicación semejante son imposibles y que, por consiguiente, la perspectiva constructivista es errónea en metafísica. Con la descripción de lo concreto el pensamiento metafísico proporciona también las condiciones de posibilidad de lo abstraíble y los límites a la posible construcción de conceptos.

El error clásico de la metafísica, su confusión de lo abstracto con lo concreto, no sólo reside, pues, en la confusión de la gramática de los lenguajes naturales con la de la lógica matemática, sino en una falsa evaluación de las condiciones específicas de aplicación de la lógica al conocimiento. La fuente de esa confusión, heredada de la ontología de la sustancia, radica en el uso como formas universales de conocimiento de los enunciados judicativos, aquellos que unen los conceptos de sujeto y predicado. Con el descubrimicnto de la metafísica de Whitehead por la filosofía alemana no sólo surgió una nueva forma de pensamiento metafísico, sino una nueva idea sobre el ser de la metafísica. Desde esta nueva perspectiva, 
la orientación antimetafísica del criticismo aparece como una reducción dogmática. La metafísica no se agota en la formulación de otros mundos y en la distinción entre dos formas correspondientes de conocimiento; tampoco en la distinción entre un mundo de aquí y otro mundo de más allá, ni en la separación de la experiencia frente al conocimiento a priori. El conocimiento metafísico es, como cualquier otro conocimiento, parte de ese mundo, y por ello se encuentra vinculado necesariamente a la experiencia. Su misión frente a cualquier experiencia dada es, al menos, doble: debe, por un lado, hacerla más visible y transparente; por otro, debe abrir nuevos horizontes para la multiplicidad de experiencias dadas. Las categorías metafísicas son válidas tanto para las experiencias de los mundos de vida multiculturales como para las múltiples experiencias de unas ciencias cada vez más diferenciadas. Como categorías y fundamentos, las ideas metafísicas permiten descripciones muy generales sobre desarrollos sencillos y complejos que persiguen sus respectivos objetivos entre el orden y el desorden, entre la estabilidad y la inestabilidad, exponiéndose en esa búsqueda a un riesgo existencial variable. En lo que atañe a las ciencias como tales, las categorías metafísicas pueden ser consideradas como condicionantes del desarrollo científico, de las posibles crisis de fundamentación y de las transformaciones de los paradigmas. Las referencias a un nuevo ethos en la metafísica confirman también que ésta ya no pretende, como antes, la construcción de sistemas conceptuales cerrados. Se encuentra más bien abierta a nuevas experiencias y, como toda experiencia, es hipotética y susceptible de ser revisada a tenor de nuevas experiencias. Su perspectiva global permite asimismo una reconsideración de la naturaleza, ya no constituida sólo por el entorno, sino por el mundo que como tal no se presta a ser objeto del conocimiento teórico y materia prima de la productividad social. El ser de la naturaleza como universo es omniabarcante y a la vez relativo con respecto a cada criatura natural que, dentro de su mundo particular, existe en el mundo global. El ser de la naturaleza incluye toda una infinidad de criaturas naturales que, desde un punto de vista metafísico, se distinguen por la multiplicidad de sus formas organizativas.

El pensamiento metafísico animado por Whitehead se distingue de la ontología fundamental precisamente por haber recuperado una visión del conjunto de la naturaleza como mundo cósmico omniabarcante y como perimundo relativo. También se distingue por ello del pensamiento hermenéutico orientado hacia las ciencias del espíritu y de la filosofía social fundada sobre una teoría de la comunicación. Pero la referencia a un nuevo ethos en el pensamiento metafísico no debe conducir a malentendidos. Esa metafísica no proporciona una nueva ética, incapacidad que quixá deba ser juzgada como su principal defecto. En cualquier caso, sí actua como crítica de la moral. Tanto lo uno como lo otro es la consecuencia de todo naturalismo. Allí donde los procesos naturales son considerados des- 
de el punto de vista del orden y del desorden, de la adaptación lograda y fallida, de la estabilidad y de la inestabilidad, se termina por reconocer que esos procesos están vinculados a la realización de unos valores. Una consideración universal de este tipo sobre los valores hace difícil, si no imposible, encontrar una vía para aquellos valores que reconocemos como éticos. El problema fundamental del naturalismo se corresponde en cierta medida con el problema básico del formalismo, enfrentado por la teoría ontológico-fundamental a la cuestión de una ética filosófica. Allí donde todas las distinciones existenciales terminan por saldarse en la distinción entre una existencia auténtica y una existencia inauténtica, la ética filosófica pierde evidentemente todo su derecho. Frente a este tipo de anti-eticismo, la filosofía alemana de las últimas décadas ha desarrollado una intensa labor sobre los fundamentos de la ética. $\mathrm{Si}$ se desease distinguir entre una ética metafísica y una ética no metafísica, el peso de la labor teórica aludida caería sin duda dentro del último ámbito. ${ }^{38} \mathrm{La}$ diferencia entre uno y otro tipo de ética depende del concepto de metafísica que se mantenga y de cómo se delimite ésta frente a la ética. La gran obra filosófico-religiosa de Franz Rosenzweig, La estrella de la redención, cuya significación para la filosofía alemana es reconocida aunque con reticencias, podría muy bien presentarse bajo el rótulo de Metafisica y ética. La obra de Rosenzweig, escrita durante el último año de la Gran Guerra, aporta un compendio único de la tradición filosófico-religiosa. En su seno confluyen las contraposiciones entre la teología y la filosofía, entre la fe y el saber, el judaísmo y el cristianismo y, en no menor medida, la contraposición histórica entre la antigüedad y la modernidad. En lo que se refiere a la filosofía en sentido estricto, esta obra crea una nueva relación entre el pensamiento de Kant y el del último Schelling, así como entre el de Schopenhauer y el de Nietzsche. El sistema del pensamiento universal aparece vinculado a la profesión personal de religiosidad. Este nuevo pensamiento puede calificarse de metafísico en la medida en que en él Dios, el mundo y el hombre son pensados en su ser-para-sí y en su confluencia histórica, como origen de la creación, de la revelación y de la redención. El hombre capacitado para la eticidad es emplazado en ese acontecer de causas y sometido a la experiencia histórico-moral originaria por la que se abre a los demás. El cántico al amor, el amoroso diálogo cntre el Yo y el Tú, entre cl individuo y la comunidad religiosa, entre el hombre y Dios, es el origen y el lugar de una eticidad que acontece por sí misma. La ética de Rosenzweig puede ser también considerada como no metafísica, ya que su representación no tiene lugar desde un punto de vista teórico, sino que apunta a la vida práctica y a la realidad de la oración.

Por otra parte, el pensamiento filosófico de Wittgenstein no es evidente desde el punto de vista de la metafísica. Pese a ello, es posible considerarlo también bajo el título de «metafísica y ética». Para Wittgenstein, la 
ética es explícitamente «trascendental», esto es, su lugar no se encuentra en el mundo y por tanto tampoco puede hablarse de ella en forma de frases, como ocurre con el mundo. Para decir algo sobre ética hay que chocar necesariamente con el lenguaje. La ética comienza allí donde termina el mundo. El centro neurálgico de la filosofía en lengua alemana radica, pues, en el ámbito de la ética no metafísica. Pero el concepto de una ética semejante comporta diversos significados. Siguiendo la idea de Joachim Ritter, puede traerse a colación la expresión clave de «rehabilitación de la filosofía prácticas. ${ }^{39}$ Con ello se alude a una tradición que se remonta desde Aristóteles hasta Christian Wolff en la que la filosofía práctica aspira a gozar de autonomía frente a la teoría pura, sin pretender por ello limitarse al ámbito de una ética pura. La filosofía práctica incluáa ahí la doctrina del hogar, de la ciencia doméstica y financiera, así como la jurisprudencia y la política. Pero también puede hablarse de una ética no metafísica en un sentido completamente distinto: aquel que obedece al espíritu y a la letra de la filosofía práctica de Kant. Sería posible incluso tomar fuera de contexto las palabras, tantas veces citadas, de Whitehead y afirmar que la literatura alemana contemporánea sobre ética filosófica consiste fundamentalmente en una serie de notas a pie de página a la obra de Kant. Sin embargo, la idea de una ética no metafísica no posee en ningún caso menor significado que la de una ética metafísica. Una ética no metafísica puede renunciar a un marco conceptual metafísico por razones fundamentalmente metodológicas y adaptarse a su propia noción del concepto. Puede prescindir del nombre y del concepto de Dios o limitarse conscientemente en sus conceptos teóricos a un mínimo metafísico. Puede prohibir incluso la deducción de cualquier principio moral, de una ley de la eticidad, a partir de premisas metafísicas para no exponerse a la acusación de que desconoce la distinción clásica entre ser y deber y que corre, por ello, el riesgo de cometer una falacia naturalista, un pecado mortal en filosofía, según ciertas concepciones. La filosofía ética, por último, puede interpretar su negativa a cualquier forma de metafísica apelando al principio de la autonomía moral. Puesto que supone la existencia de unos mandamientos y prohibiciones éticas válidas para todos los hombres por igual, no busca ya el fundamento de su vinculatoriedad en la voluntad despótica de un ser supremo, cuya autoridad exige la ciega obediencia, sino en el ideal ético de la razón práctica de la voluntad. La mayor parte de los esfuerzos teóricos en alemán dedicados a la ética filosófica son deudores de la filosofía práctica de Kant. No desean conformarse con la delimitación conceptual de lo ético frente a lo no ético, en el sentido de una metaética analítica, pero tampoco se satisfacen con la descripción de unos sistemas concretos e históricamente determinados de normas éticas y políticas, una misión más propia de ciencias como la etnología y la sociología empírica. 
La filosofia alemana contemporánea reconoce la necesidad de acometer una fundamentación de la ética, una ética universal, válida para todos los hombres. Esta misión se contempla a menudo con la idea y el espíritu de la Ilustración, asociándola injustificadamente y de inmediato a la imagen de la ética no metafísica. La crítica kantiana de la razón sigue siendo paradigmática tanto en la determinación de los objetivos como en su realización. Esto no sólo es válido para la idea de una fundamentación en general, sino para la posibilidad de una ética aplicada al procedimiento deductivo trascendental kantiano. Aunque una aplicación semejante no sea posible en sus diversos pasos, puede verse en ella un intento ejemplar por formular la racionalidad filosófica. El debate en pro y en contra de los "argumentos trascendentales ${ }^{40}$ ha de valorarse como un intento por sondear la racionalidad filosófica de la argumentación y de la fundamentación con respecto a la ética. Los esfuerzos por mejorar la concepción de los principios de la apercepción trascendental y de la voluntad pura de las personas racionales pertenecen también a ese contexto que pretende modificar tentativamente el método trascendental kantiano. Algunos autores se conforman con el supuesto pragmático de que existe en los hombres algo así como un common sense, una razón práctica que justifica la ampliación de la esfera de la eticidad pura e incondicionada en un sentido utilitarista. Otros filósofos se han esforzado por conseguir una "transformación" profunda de la filosofia kantiana de la subjetividad trascendental que permita evitar las aporías de sus principios. Entre ellos se cuentan J. Habermas y K.O. Apel, con su idea de una comunidad universal de comunicación acentuada en cada caso de forma diversa frente a la dimensión hermenéutica.

\section{La autocomprensión histórica de la filosofía contemporánea en la modernidad}

La filosofía práctica kantiana no ha influido como paradigma sólo por su repertorio conceptual para la fundamentación filosófica, sino también por su carácter como ética de un deber incondicionado. Sin embargo, las agudas contradicciones que servían para acentuar la incondicionalidad de ese deber se han aplacado y han dado lugar a diversos acomodos. Entre los múltiples esfuerzos por equilibar las agudas contradicciones de la ética kantiana habrá que mencionar, cn primer lugar, aquellos que tengan más en cuenta la necesidad humana de felicidad, aquellos que no quieran confiar la sociabilidad moralmente constituida al sentimiento racional del respeto, sino a la compasión y a la buena voluntad. En esa misma dirección corren los intentos por conciliar la inteligencia y la eticidad, así como por reducir el hiato existente entre una metafísica de las costumbres y una moral empírica. El mismo sentido posee la idea de relativizar la diferencia existente entre una acción conforme al deber y una acción obligada. En la 
filosofía contemporánea en lengua alemana se observa una estrecha vinculación entre la reflexión ética y la conciencia histórica que se esfuerza por determinar su lugar en el tiempo. Por ello, es precisamente la conciencia del poder casi ilimitado de la cultura y de la ciencia contemporánea lo que ha llevado a reconsiderar una distinción ya clásica desde David Hume: la de ser y deber. La discusión sobre los juicios de valor inaugurada por Max Weber continúa hasta nuestros días, en parte oculta bajo nuevos problemas y, en parte, abiertamente mediante nuevos argumentos que pretenden recoger las transformaciones sufridas por las condiciones de vida en un mundo científico-técnico. Pero la cuestión de los pros y los contras de la renuncia a los juicios de valor en la ciencia trasciende el ámbito de la sociología y llega a involucrar a las ciencias naturales. Es un problema que no se agota en una ponderación general de las ventajas reportadas por semejante renuncia, sino que conduce a cuestiones básicas de la lógica científica, las cuales, a su vez, motivan el reconocimiento histórico de tradiciones normativas surgidas con el desarrollo de la ciencia. ${ }^{41}$ Intereses tan opuestos como los de la hermenéutica, nacida de las ciencias del espíritu, y los de la historia de las ciencias naturales, proveniente de la lógica científica, se han unido en la consideración del problema. Cuestiones como el abismal peligro que afronta la humanidad en un planeta sobrepoblado, la carencia de alimentos en el tercer mundo, el desarrollo de armas cada vez más mortíferas y la progresiva destrucción del medio ambiente han agudizado la toma de conciencia de la filosofía alemana sobre la responsabilidad de la ciencia con respecto a las consecuencias de sus actos. Frente a los peligros que se ciernen sobre el medio ambiente, sobre las plantas y los animales, no parecen bastar las máximas utilitaristas que apelan a una limitación de los daños. Desde diversos ámbitos se está exigiendo, bajo la influencia de Hans Joas, una nueva ética de la responsabilidad cuyo referente lo constituya la humanidad futura, y no sólo la presente, y de la que pueda derivarse una nueva relación con la naturaleza en general y con todas sus criaturas. ${ }^{42}$

Entre las numerosas voces que se han pronunciado sobre esta cuestión se encuentra la de Robert Spaemann, al que la filosofía alemana debe uno de los libros de ética más "sabios" de los últimos tiempos. ${ }^{43}$ Spaemann ve claramente que los discursos sobre la fundamentación y la justificación moral han de ir precedidos de una capacidad originaria de percepción moral en los hombres: la capacidad de captar a través de los sentidos la bondad y la maldad de las criaturas y de encontrar a través de esa percepción una respuesta moral no alumbrada exclusivamente por la pura razón. Esta experiencia moral básica se encuentra inserta en el orden de la naturaleza viva. Se trata de un orden teleológicamente determinado que muestra una estructura, el ordo amoris, en cuyo culmen se sitúa el amor divino. La filosofía ética conectà aquí de forma evidente con la tradición 
metafísica que, en otro ámbito, se deseaba precisamente excluir. La filosofía en lengua alemana, pues, se plantea de forma muy consciente en sus reflexiones éticas el problema de su propia contemporaneidad. También ha intervenido en algunos casos en el debate, proveniente de Francia, sobre la denominada postmodernidad. Pero su labor filosófica más profunda y de más largo alcance ha versado sobre la modemidad, en la que ha rastrcado los comienzos y las características específicamente modernas de nuestra época con el fin de descubrir lo que ha ocurrido y lo que está a punto de ocurrir con ellas. En este reconocimiento histórico, el concepto de autoconservación como expresión específica de la modernidad ha desempeñado un papel particular. ${ }^{44}$ La reflexión histórica de la filosofía alemana guarda intencionadamente las distancias frente a la clásica filosofía histórica del idealismo trascendental y especulativo, sin negar por ello sus propios elementos teleológicos y normativos. Cuando se especula sobre la idea del progreso o de la decadencia histórica se hace siempre desde una distancia reflexiva y con unas dosis de prevención histórico-científica tales que se termina por relativizar la validez de semejante idea. El proyecto heideggeriano sobre una historia del ser compuesta de palabras primigenias es considerado sólo como una parte de su obra tardía. Hans Blumenberg presentó su gran investigación sobre La legitimación de la modemidad en consonancia con el signo de nuestra contingencia histórica ${ }^{45}$ En nuestro tiempo, la reflexión histórico-filosófica acude sólo a conceptos pensados históricamente, con preferencia de aquellos de los que se sirve la ingenua conciencia histórica contemporánea. Conceptos, por ejemplo, como el de secularización, el de curiosidad científica, el de época o el de los umbrales históricos. Ocasionalmente se cuentan historias sobre estos conceptos en las que se incluyen topoi y argumentos e incluso sucesos decisivos en la vida de personajes históricos, pero esas historias ocasionales tan sólo se engarzan de forma contingente. Esta contingencia responde a la finitud del hombre histórico y al carácter de su conciencia histórica. Con la historización de todos los conceptos relevantes para la autocomprensión histórica culmina la inversión de una perspectiva. En el fluir de lo pretérito se muestra un ahora que permanece.

\section{NOTAS}

1. La presente investigación toma como referencia el conjunto del ámbito germanoparlante (con excepción de la antigua República Democrática Alernana), por lo que subyace a la misma una cierta perspectiva agermano-federal». Para una visión global del presente siglo, cfr. Stcgmüller, W.: Hauptströmungen der Gegenwartsphilosophie ( 3 vols.), 7,a edición ampliada, Stuttgart, 1986; F. Chatelet et. al: Histoire de la Philosophie, vol. VW; Speck, J. (ed.): Grundprobletne der großen Philosophen. Philosophie der Gegenwart. Gotinga, 1972, así como mis es* tudios: Einleitung zu Geschichte der Philosophie in Text und Darstellung, vol. VIII (Siglo XX), ed. por R. Wiehl, Stuttgart, 1981, pp. 7-51; aMetaphysische Entwürfe im 20. Jahrhundert», en 
Metaphysik nach Kant?, ed. por D. Henrich y R.P. Horstmann, Stuttgart, 1988, pp. 275-296. Estos dos últimos textos ofrecen una serie de reflexiones sistemáticas sobre algunos autores tratados aquí tan sólo sumariamente por razones de espacio. Para el desarrollo de la filosofia alemana hasta 1933, cfr. especialmente Schnädelbach, H.: Philosophie in Deutschland (18311933), Francfort, 1983.

2. H.M. Baumgartner y H.M. Sass ofrecen una concisa panorámica sobre algunas tendencias fundamentales del desarrollo filosófico desde 1945 en: Philosophie in Deutschland 1945-1975. Standpunkte, Entwicklungen, Literatzir; Königstein, 1980.

3. Las obras de Albert Carnus y Jean-Paul Sartre que aparecerán citadas aquí fueron traducidas al alemán inmediatamente después de la segunda guerra mundial. Así, por ejemplo, Le mythe de Sisyphe, de 1942 (en alemán en 1950); Lhomme révolté, de 1951 (en alemán en 1952); L'étre et le néant. Essai d'une ontologie phénomenologique, de 1943 (en alemán en 1952); L'existencialisme est un humanisme, de 1946 (en alemán en 1947). La discusión de la época se vio notablemente influida por la réplica de Heidegger a Sartre en Brief über den Humanismus (1947).

4. Sobre el desarrollo del marxismo en la Alcmania de postguerra, fr, Vranicki, P.: Geschichte des Marxismus (2 vols.), Francfort, 1974, p. 2817 y ss. El diálogo cristiano-marxista, avivado por vez primera por Ennst Bloch en la República Federal en 1959 con la publicación de El principio esperanza, alcanzó su punto álgido a finales de los años sesenta. En una bibliografia editada por el Consejo Ecuménico de Ginebra en 1969 aparecian, por ejemplo, más de mil títulos.

5. Gadamer, H. G.: Wahtheit und Methode. Grundzüge einer philosophischen Hermeneutik, Tubinga, 1960. Ahora en Gesammelte Werke, vol. 1, Tubinga, 1986. Un detallado análisis de la discusión hermenéutica de los años 60 es el realizado por Pöggeler, O.: Einfühnung zu Hemeneutische Philosophie, Munich, 1972, pp. 7-71.

6. Horkheimer, M.; Adorno, Th.W. Dialektik der Aufktärung (1944); ahora en Adorno, Th. W: Gesammelte Schriften (vol. 3), Francfort, 1981. Sobre la historia de la Escuela de Frankfunt cfr. el amplio estudio histórico de Wiggershaus, R.: Die Frankfunter Schule. Geschichte, Theoretische Entwickiung, Politische Bedeutung, Munich, 1986.

7. Cfr. Habermas, J.: Theorie und Praxis. Sozialphilosophische Studien, Neuwied, 1963; Zur Logik der Sozialwissenschaften, Tubinga, 1967; Erkenntnis und Interesse, Francfort, 1968; sobre la controversia entre Gadamer y Habermas, cfr. Apel, O. et. al.: Hermenestik tnd Ideotogiekritik, Francfort, 1971.

8. Lorenzen, P.: Methodisches Denken, Francfort, 1968; Konstruktive Wissenschaftstheorie, Francfort, 1974; Id. Kamlah, W.: Logische Propädeutik, Mannheim, 1967; Id. Lorenz, K.: Dialogische Logik, Darmstadt, 1978; Mittelstrass, J.: Die Rettung der Phänomene. Ursprung und Geschichte eines antiken Forschungsprinzips, Berlín, 1962.

9. En este punto hay que mencionar dos concepciones radicalnente distintas del problema: los trabajos de Blumenberg Die Genesis der kopernikanischen Welt, Francfort, 1975, y Lebenszeit und Weltzeit, Francfort, 1986, así como la obra en varios volúmenes de Schmitz, H.: System der Philosophie, Bonn, 1964.

10. Dilthey, W.: Einleitung in die Geisteswissenschaften (1883), en Gesammelte Schriften, vol. 1, 120, y su póstumo Entwïrfe zur Kritik der historischen Vemunft, vol. 7, p. 191 y ss.

11. Weber, M.: Die protestantische Ethik und der Geist des Kapitalismis, Wirtschaft und Gesellschaft, Tubinga, 1922.

12. Husser, E.: Die Krisis der europäischen Wissenschaften und die traszendentale Phänomenologie. Eine Einleitung in die phänomenologische Philosophie (1936), en Hussertiana, vol. VI.

13. Heidegger, M.: Sein und Zeit (1927), ahora en Gesamtaufgabe vol. 2, Francfort, 1977.

14. Cfr. Gaiser, K.: Platons ungeschriebene Lehre. Studien zur systematischen und geschichtlichen Begruindung der Wissenschaften in der platonischen Schule, Stuttgart, 1968, y Krämer, H.J.: Arete bei Platon und Anistoteles. Zur Wesen und zur Geschichte der platonischen Ontologie, Heidelberg, 1959. Para la discusión sobre la denominada doctrina no escrita de Platón cfr., por 
ejemplo, la colección de ensayos de Wippern, J. (ed.): Das Problem der ungeschriabenen Lehre Platons. Beiträge zum Verstänänis der platonischen Prinzipienphilosophie, Darmstadt, 1972.

15. Junto con las lecciones de Marburgo, $f f$. al respecto Phäromenologische Interpretationen zu Arisloteles. Einführung in die phänomenologische Forschung (1921-1922). Gesamtausgabe, vol. 61, Francfort, 1985.

16. Cfr. Gadamer, H.G.: Die Idee des Guten zwischen Plato und Aristoteles, Heidelberg, 1978; Bubner, R.: Handlung, Sprache und Vemunft. Grundbegriffe praktischer Philosophie. Francfort, 1982.

17. Spaemann, R.: Gituck und Wohlwollen. Versuch uber Ethik, Stuttgart, 1988; id. Löw, R: Die Frage wozu? Geschichte und Wiederentdeckung des teleologischen Denkents, Munich, 1981.

18. Cir. al respecto las actas de los congresos sobre Hegel publicadas desde 1964 por las editoriales Bouvier y Klett-Cotta, las cuales constituyen, sin embargo, sólo una parte de las publicaciones de la Internationale Hegel-Vereinigung. $C F$, asimismo la colección Idealismo alemán editada por R. Bubner, K. Cramer, R. Wiehl, W. Wieland et. al. en Klett-Cotta, 1981 yss.

19. Cfr. Henrich, D. (ed.): G.W.F. Hegel, Philosophie des Rechts. Die Vonlesung von $1818 / 1919$ in einer Nachschnift. Francfort, 1983; Ilting, K.H. (ed.): G.W.F. Hegel, Die Philosophie des Rechts. Die Mitschriften von Wannemann (Heidelberg 1817-1918) und Homeyer (1818-1819), Stuttgart, 1983.

20. En este sentido hay que destacar los numerosos trabajos de Dieter Henrich (Fichtes urspringliche Einsicht, Francfort. 1967; Selbstverhaltrisse. Gedanken und Auslegungen zu den Grundlagen der klassischen deutschen Philosophie. Stuttgart, 1982) y de sus discípulos, por ejemplo U. Pothast: Uber einige Fragen der Selbstbeziehung, Francfort, 1971.

21. Cassirer, E.: Philosophie der symboltschen Formen (1923), Darmstadt, 1953-1954. El renovado interes por la filosofia de Cassirer aparece documentado, por ejemplo, en la reciente recopilación de H.J. Braun, H. Holzey y E.W. Orth: Uber Emst Cassivers Philosophie der symbolischen Fomen, Francfort, 1988.

22. Actualmente no puede encontrarse un equivalente a los intentos por establecer una discusión sistemática con el psicoanâlisis freudiano como la que tuvo lugar en el ámbito alemán por parte de la Teoria Crítica (H. Marcuse, E. Fromm, J. Habermas) y del existencialismo ( $L$. Binswanger). No obstante, no faltan investigaciones hermenéuticas sobre la teoria psicoanalítica, como la de H. Lang: Die Sprache und das Unbewußte. Jacques Lacans Grundlegutig der Psychoanalyse. Francfort, 1986.

23. Cfr. sobre todo la publicacion por W. Schmied-Kowarzik de las actas del congreso Der Philosoph Franz Rosenzweig (1886-1929), 2 vols., Friburgo, 1988, con colaboraciones de W. Marx, R. Wiehl, M. Benedikt y $O$. Pöggeler.

24. Sobre el Circulo de Viena existe desde 1986 la colección Wiener-Kreis. Schriften zum logischen Empinismus, ed. por H. Mulder, A.J. Knox, R. Hegselmann y F. Stadler en Suhrkamp Verlag. Con ella están saliendo a la luz los documentos y trabajos no publicados del Archivo sobre el Circulo de Viena en Amsterdam. También han de tenerse en cuenta los trabajos de Haller, R.: Fragen zu Wittgenstein und Aufsätze zur österreichischen Philosophie, Amsterdarn, 1986, e id. Stadler, F. (eds.): Ernst Mach. Werk und Wirkung, Viena, 1988. De la creciente actualidad de la filosofia de Whitehead en el rnundo germanoparlante dan fe las dos obras colectivas: Whitehead und der Prozeßbegriff. ed. por H. Holz, Friburgo, 1984, y Whiteheads Metaphysik der Kreativitat, ed. por F. Rapp y R. Wiehl, Friburgo, 1986.

25. Stegmüller, W.: Probleme und Resultate der Wissenschaftstheorie und Analytischen Philosophie, Berlín, 1969 y ss. Otras investigaciones más detalladas sobre importantes problemas teórico-científicos han sido las llevadas a cabo, entre otros, por E. Scheibe: Die Kontingenten Aussagen in der Physik. Axiomatische Untersuchungen zur Ontologie der klassischen Physik und der Quantentheorie, Francfort, 1964.

26. Cfr., por ejemplo, Wiehl, R.: Der Begriff in den Anschauangsfomen der Mittelbarkeit und Unmittelbarkeit, nebst einem Anhang über die Kathegonien in Whiteheads "Process and Re- 
ality* (manuscrito), Francfort, 1961, asi como «Einleinung in die Philosophie A.N. Whiteheads» en Adventures of Ideas (traducido al alemán por E. Bubser), Francfort 1971, pp. 7-71.

27. Tugendhat, E.: Vorlesungen zur Einfiibrung in die sprachanalytische Philosophie, Francfort, 1976; Selbstbewußtsein und Selbstbestimmung. Sprachanalytische Interpretationen. Francfort, 1979. Cfr. asimismo los dos volúmenes colectivos editados por P. Bieri: Analytische Philosophie der Geistes, Königstein, 1981, y Analytische Philosophie der Enkenntnis, Francfort, 1987. En ellos se ofroce una versión en alemán de los principales textos filosóficos anglosajones asi como una amplia bibliografía. Para un análisis más detallado, cfr. Künne, W.: Abstrakte Gegenstände Semantik und Ontologie, Francfort, 1983.

28. Entre esas investigaciones habría que destacar los trabajos de D. Henrich sobre el idealismo alemán ( $f$ r. nota 20) junto con una serie mucho más amplia: Wieland, W., Die aristotelische Physik. Untersuchungen über die Grundlegung der Naturvissenschaft und die sprachlichen Bedingungen der Prinzipienforschung bei Aristoteles, Gotinga, 1970, el reciente comentario de M. Frede y G. Patzig al séptimo libro de la Metafísica de Aristóteles: Aristoteles Metaphysik Text, Übersetzung und Kommentar, Munich, 1988; Beierwaltes, W.: Denken des Einen. Studien zur Neuplatonischen Philosophie und ihrer Wirkungsgeschichte, Francfort, 1985; Flasch, K: Einführung in die Philosophie des Mittelalters, Darmstadt, 1987; Schulz, W.: Die Vollendung des deutschen Idealismus in der Spätphilosophie Schellings, Stuttgart, 1965; Prauss, G.: Kant und das Problem der Dinge an sich, Bonn, 1975; Cramer, K. Nicht-reine synthetische Urteile a priori ein Problem der Traszendentalphilosophie I. Kants, Heidelberg, 1985; por último, Tugendhat, E.: Der Wahrheitsbegriff bei Hussen und Heidegger, Betin, 1970. Igualmente habria que citar magníficas ediciones de obras completas, como por ejemplo las de Nicolás de Cusa, a cargo de la Academia de Ciencias de Heidelberg, la edición crítica de la obra de Fichte y de Schelling, bajo la dirección de la Academia de Ciencias de Baviera, o la Husserliana, que actualmente se encuentra en proceso de edición en Holanda con el patrocinio del Archivo Hussen de Colonia y de Friburgo. Por último, no puede olvidarse el proyecto del Diccionario histórico de Filosoffa, editado desde 1971 por la Wissenschaftliche Buchgesellschaft de Darmstadt bajo la dirección de J. Ritter ( 7 volúmenes hasta la fecha).

29. Habermas, J.: Theorie des kommuntikativen Handelns, 2 vols., Francfort, 1981; Vorstudien und Ergänzungen zur Theorie des kommunikativen Handeins, Francfort, 1984; Apel, K.O.: Transformation der Philosophie, 2 vols., Francfort, 1972, y Die Erklären-Verstehen Kontroverse in transzendental-pragmatischer Hinsicht, Francfort, 1979. Sobre la configuración del pragmauismo a lo largo del presente siglo, cfr. Stachowiak, H. (ed.): Handbuch des pragmarischen Denkens, 4 vols., Hamburgo, 1986 y ss. Sobre el problema de la intersubjetividad, cfr. Theunissen, M.: Der Andere. Studien zur Sozialontologie der Gegenwart, Berlin, 1977.

30. No es casual que el interés por el tema en el ámbito lingüístico alemán se haya concentrado ante todo en la filosofía de la técnica. En este contexto habría que aludir, fundamentalmente, a los trabajos de F. Rapp. Para una panorámica sobne las discusiones más recientes en este campo cfr. Durbin, P.T. y Rapp, F. (eds.): Technikphilosophie in der Diskussion Ergebrisse eines deutsch-amerikanischen Symposions in Bad Homburg, Brunswich, 1982.

31. Algunos de los problemas que trato a continuación de forma necesariamente resumida aparecen expuestos con mayor detalle en mi artículo aDie Komplementarität von Selbstsein und Selbstbewaßtsein», en Benedikt, M. y Burger, R. (eds): Bewruprsein, Sprache und die Kunst. Metamorphosen der Wirklichkeit, Viena, 1988, pp. 149-177. Para una discusión más reciente sobre el tema, cfr. las contribuciones del homenaje a D. Henrich publicadas en Cramer, H. et al. (eds.): Theorie der Subjektivität, Francfort, 1987.

32. Sobre Tugendhat, ofr. la ya mencionada lección sobre Selbstbewußtsein und Selbstbes-

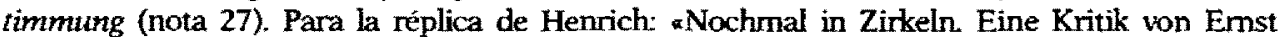
Tugendhats semantischer Erklärung von Selbstbewußisein», en Bellut, C. y Müller-Schöll, U. (eds): Mensch und Modeme. Beiträge zur philosophischen Antropologie und Gesellschaftskritik (Homenaje a H. Fahrenbach), Wurzburgo, 1989, pp. 93-132.

33. Cfr. Peirce, Ch.S.: Schriften zum Pragmatiomus und Pragmatizismus, ed. por K.O. Apel y trad. por $G$. Wartenberg, Francfort, 1976. El volumen contiene los textos de Peirce, ya edita- 
dos en su día por Apel, Schriften I y Schriften II, Francfort, 1967 y 1970. La introducción a ambas ediciones se encuentra resumida en Apel, K.O.: Der Denkweg von Charles Sanders Peirce. Eine Einfuhrung in den amerikanischen Pragmatismus, Francfort, 1975.

34. Cfr. Wiehl, R.: "Heideggers ontologische Frage und die Möglichkeit einer Ontologie», Neue Hefie für Philosophie, 23 (1984), 23-45. En la literatura más reciente se observa un esfuerzo por no limitarse a una presentación comentada y sistematizada de la filosofía de Heidegger; cfr. Marx, W.: Heidegger und die Tradition. Eine Problengeschichtiche Einführung in die Grundbestimmungen des Seins, Hamburgo, 1980; Gethmann, C.F.: Verstehen und Auslegung. Das Methodenproblem in der Philosophie Martin Heideggers, Bonn, 1974; Rentsch, T.: Heidegger und Wittgenstein. Existenzial und Sprachanalysen zu den Grundlagen philosophischer Anthropologie, Stuttgart, 1975; Figal, G.: Mantin Heidegger, Phänomenologie der Freiheit. Francfort, 1988. Para los puntos siguientes, ofr. Wahrheit und Methode y el vol, 3 de las obras de Gadamer (Neusere Philosophie: Hegel, Husserl, Heidegger), Tubinga, 1987.

35. Esto es algo que ha quedado claramente documentado en la reciente obra, editada por von Hermann, F.W. Beiträge ztur Philosophtie (Vom Ereignis), GA 65, Francfort, 1989.

36. Sobre esta controversia, of. Apel, K.O. et. al. (eds.): Neue Versuche über Erklären tund Verstehen, Francfort, 1978 (cfr. nota 29) y Riedel, M.: Verstehen oder Evklären? Zur Theorie und Geschichte der hermeneutischen Wisserischaft.

37. Cramer, W.: Grundlegung einer Theorie des Geistes, 2." ed. ampliada, Francfort, 1965. Sobre la filosofía de Cramer cfr. los dos volúmenes colectivos Subjektivität una Metaphysik. Festschrift für Wolfgang Cramer, ed. de D. Henrich y H. Wagner, Francfort, 1966, y Rationale Metaphysik. Die Philosophie von Wolfgang Cramer, vol. 1, ed. de H. Radermacher y P. Reisinger, Stuttgart, 1987 (con una bibliografía de los escritos de Cramer).

38. Así, G. Patzig ha presentado sus análisis sobre el problema de la ética bajo el título programatico de Ethik ohne Metaphysik.

39. Cfr. Ritter, J.: "Zur Grundlegung der praktischen Philosophie bei Aristoteles", Archiv fär Rechts - und Sozialphilosophie, 46 (1960), pp. 179-199. Para la discusión suscitada por esta obra, cfr. Riedel, M. (ed.): Rehabilitierung der praktischen Philosophie, 2 vols., Friburgo, 197274.

40. Cfr. Bieri, P; Horstmann, R.P.; Krüger, L. (eds.): Trascendental Arguments and Science. Essays in Evistemology, Dordrecht, 1979.

41. C/r., por ejemplo, el estudio publicado por el Instituto Max-Planck sobre las condiciones de vida del mundo científico-técnico: Die gesellschafitiche Orientierung des wisseraschaftichen Fontschritts, Francfort, 1978. Para el debate sobre las tesis de T.S. Kuhn, cfr. HoyningenHuene, P.: Die Wissenschaftsphilosophie Thomas S. Kuhns. Rekonstruktion - und Grundlagenprobleme, Brunswich, 1989. Tambien llirsch, G. (ed.): Wozu Wissenschafisphilosophie? Positionen und Fragen zur gegenuärtigen Wissenschaftsphilosophie, Berlín, 1988.

42. Joas, H.: Das Prinzip Verontwortung, Francfort, 1979.

43. Cfr. la nota 17 , en la que se hace referencia a la obra de Spaemann Verstuch uber Ethik.

44. Cfr. el volumen editado e introducido por $\mathrm{H}$. Ebeling: Subjektivitât und Selbsterhalturng. Beitrüge zur Diagnose der Modeme, Francfort. 1976.

45. Blumenberg, H.: Die Legitimität der Neuzeit, Francfort, 1966 (revisada y reeditada en 1973). 